\title{
We Probably Thought That Would Be True: Perceiving Complex Emotional States in Nonhumans
}

Victoria Braithwaite. 2010. Do Fish Feel Pain? Oxford University Press, New York. Pp. 256. \$35.00 (hardcover). ISBN 9780199551200.

Barbara J. King. 2013. How Animals Grieve. University of Chicago Press, Chicago. Pp. 208, 7 halftones. $\$ 25.00$ (cloth). ISBN 9780226436944.

Reviewed by Raymond Pierotti ${ }^{1^{*}}$ and Cynthia Annett ${ }^{2}$

Reviewer address: ${ }^{1}$ Ecology and Evolutionary Biology, University of Kansas, Lawrence, KS 66045-2106, ${ }^{2}$ Department of Biological Sciences, University of Alaska Anchorage, Anchorage, AK 99507

*Corresponding author: pierotti@ku.edu

Received: July 5, 2013

Volume: 5:15-21

Published: January 13, 2014

(C) 2014 Society of Ethnobiology

In 1983 the Cherokee poet Jimmy Durham wrote a poem titled "Teachings of my Grandmother" which begins:

In a magazine too expensive to buy, I read about How, with scientific devices of great complexity US scientists have discovered that if a rat Is placed in a cage in which it has previously Been given an electrical shock, it starts crying.

I told my Grandmother about that and she said, "We probably knew that would be true" (Durham 1983)

While reading the two books listed above, our thoughts turned frequently to the knowledge of Durham's grandmother and of grandmothers everywhere. Why do we find it necessary to ask questions like this when the answers seem obvious? That is, why do people of European ancestry, including scientists, insist on arguing that our nonhuman relatives are incapable of achieving complex behavioral states when it should be obvious that they can, just from our interactions with animals in our everyday lives?

This tendency is likely a result of differences in cultural traditions, although it is also clearly linked to the concept of what is considered to be "science" or scientific. It seems likely that the attitudes of scientists in cases like this may be a major reason why many Indigenous people argue that they don't have "science," even though they have well worked out systems of close observation of natural phenomena that allow them a sophisticated understanding of the natural world (Pierotti 2011).

The reason that such issues are of concern to ethnobiology is that much of our scholarship operates within the zone circumscribed by these competing views of nature (Anderson 2013). We are scientists who operate mostly in the Western tradition, yet the questions we choose to investigate allow us understanding of, and sometimes identification with, the knowledge traditions of non-Western cultures that informs the work of many of our top scholars, as exemplified in works like Gene Anderson's Ecologies of the Heart (1996). Another factor that predisposes ethnobiologists to a more open and flexible perspective with regard to nonhumans is that we represent a deliberate attempt to merge two fields, anthropology and biology, although the biology practiced by ethnobiologists deals more with ecosystems and populations than the practices of laboratory oriented scholars who deal primarily or exclusively with cells and molecules.

One thing that is obvious in reading these books together is that anthropologists sometimes rush in where biologists oft fear to tread. Braithwaite, a Professor of Fisheries at Penn State, gives her (2010) book the relatively limp title, Do Fish Feel Pain? In contrast, King, an anthropologist at William and Mary, leaps right into the breach with the title, How Animals Grieve, avoiding both the dreaded question mark, and establishing that from her perspective, 
there is no question that nonhuman animals are, in fact, capable of experiencing grief.

One oddity is that, although both of these books are published by major academic presses, neither is a truly scholarly work with complete citations of sources (even of important examples), or presentations of the actual data; in fact, neither volume includes a single illustration. Both books depend upon closely argued examples in the Darwinian tradition, and as with Darwin's original work, appear to be targeted at that audience consisting of educated laypeople, scholars from other disciplines, university administrators, and those responsible for ethical decisions at the political level.

To begin with Braithwaite's Do Fish Feel Pain? (henceforth DFFP), one of us Raymond Pierotti (RP) was first exposed to this issue as a graduate student in the late 1970s, when a fellow grad student in ichthyology said at a social gathering, "We don't even know if fish feel pain." I confess that my initial reaction was similar to that described for Jimmy Durham's grandmother, but I was made to realize that this was a serious issue to many biologists. About a decade later I watched a dear friend and close colleague take a live and active fish from a tank, lay it on a table and remove one of its eyes, with no apparent consideration of anesthesia. Observing this made me realize that I was very naive concerning the attitudes of lab biologists. I then determined to devote myself more to this issue. In consequence, I am now the longest tenured member of my university's Institutional Animal Care and Use Committee (IACUC) at seventeen years.

The issue of suffering in fish still arises at irregular intervals during IACUC discussions. One of the more compelling issues is, "Exactly how does one decapitate a fish?" considering that they have no obvious division between head and trunk. For us the issue of sentience and complex behavior in fish was settled when we spent a couple of seasons watching biparental care in cichlids (Tilapia mariae Boulenger Cichlidae) in the channelized rivers surrounding the Florida Everglades. This species showed clearly differentiated parental roles, with females performing nearly all tending of eggs and most tending of free embryos. After young became free-swimming and left the nest, however, males took over primary tending of the free swimming young while the smaller females patrolled the perimeter of the school and performed nearly all chases directed at predators.
Males and females traded off vigilance and feeding, and showed a high degree of intrapair coordination (Annett et al. 1999). Under dense nesting conditions in this species, we observed adoption of broods, group rearing of free-swimming young and the presence of non-breeder 'satellites' sharing and defending a territory with breeders. The level of complexity we observed in these fish was comparable to the behavior we had observed in monogamous birds (Pierotti and Annett 1994, 1995; Pierotti et al. 1996). It seems obvious that fish were capable of complex social behavior. Equally obvious was our conclusion that the issue over complexity of fish behavior might be settled if scientists dealing with this question actually spent any time watching their study organisms in their natural environments.

In DFFP Braithwaite describes her work on the presence of nociceptors (cells located in the epidermis that perceive painful stimuli) in fishes. Since nociceptors exist in birds, mammals, and amphibians, and even in invertebrates, it should be expected that they would be found in fishes as well. The null hypothesis should be: "This feature exists in a wide range of organisms, hence we assume that it exists in fishes as well," which would be the Darwinian perspective. But there seems to be an odd logic amongst scientists that historically gave us the opposite: "We assume that if a given structure has not been proven to exist in a particular organism, the null hypothesis is that it does not exist, despite its proven existence in closely related forms." Fish, by this reasoning, were assumed not to have nociceptors despite their established presence in every other lineage of vertebrates.

This line of thinking invariably works to the benefit of economic (sometimes referred to as "pragmatic") interests, especially food industries, including the aquaculture, commercial, and sport fishing industries in the case of fishes. When scientific reasoning is influenced by the economic system predominant in our society, there may well be a greater tendency to take a non-Darwinian approach such as arguing that relatedness does not predict whether an organism has particular traits, and therefore allow us to assume that an economically important animal lacks the ability to feel pain until proven otherwise. Taking this a step further, in the U.S., which probably represents the most economically driven philosophical system in history, this attitude goes hand in hand with a tendency on the part of much of the public to oppose the teaching of Darwin- 
ian thinking in schools. Darwinian thought assumes relatedness and the existence of shared traits among related species, and actually shares many concepts with Indigenous knowledge (see chapter 6 in Pierotti 2011). What goes unrecognized and unacknowledged by most Western scientists is that the "objectivity" or "pragmatism" expected of their scientists, ends up being used to deny identity between obviously homologous traits in humans and other species, which is, in essence, creationist thought.

A similar approach can be found in attempts by the American Veterinary Association and the Humane Society of the United States to argue that rabies vaccines approved for use in domestic dogs, should not also be used in their ancestral congeners, gray wolves (Canis lupus Linnaeus Canidae), even though the same vaccine is approved for use in cats (Felis sylvestris Linnaeus Felidae), cattle (Bos taurus Linnaeus Bovidae), and horses (Equus caballus Linnaeus Equidae) (see pages 93-94 in Pierotti 2011). What is striking is how mute many scientists become when faced with such obvious sophistry.

According to Braithwaite, simply demonstrating the presence of nociceptors was not considered sufficient to demonstrate that fish feel pain, it was also necessary to demonstrate that fish show behavioral responses to painful stimuli that are the same as those observed in birds and mammals, i.e., showing obvious changes in behavior in response to "painful stimuli." One reason for requiring such evidence is apparently based upon the argument that because hooked fish pull and try to swim away, the hook does not really cause them pain. Braithwaite, however, correctly points out that the situation is more complicated than this. A nociceptive response to a painful stimulus may indeed involve an escape or flight response. When any vertebrate, including humans, are trapped or caught, their bodies experience a range of responses, often not involving conscious thought, typical of nociceptive responses. For example, people who lose limbs in accidents often try to run, or may even pick up the severed limb, without feeling apparent pain (for several cinematic but fact-based examples, watch the opening section of Steven Spielberg's Saving Private Ryan). As Braithwaite states, "The motivation to escape is so strong that the (individual) works to overcome any pain to try and get away" (p. 165).

This last point suggests an issue that is rarely, if ever, raised: "How do we know that humans feel pain?” Raymond Pierotti asked his fellow graduate student this exact question in 1978 in response to his statement concerning our lack of knowledge concerning pain in fish. The answer seems to be that we can talk to humans. There is, however, no quantifiable basis for pain, even in humans. We ask humans to assess their own levels of pain and there is no way of verifying that one person's level 10 is different than another's level 7. As Braihwaite indicates, we have trouble identifying subjective pain in fishes; however, "we would probably struggle to do this for any human if we could not understand their language" (p. 106, emphasis added).

This entire debate is basically a legacy of the Cartesian machine metaphor, which argues that nonhumans are "machines, who cannot suffer, but only malfunction." It needs to be kept in mind that despite his contributions to the history of science, Descartes was very much a creationist by today's standards, and his "philosophy" is rooted in the Christian tradition, e.g., the discussion of souls, whose existence has never been demonstrated by "objective" science. This logic was even applied to non-European Homo sapiens, and there have been numerous episodes where individuals of European ancestry have questioned the humanity, the emotional responsiveness, and the existence of "souls" in people whose skin color did not match theirs, especially those who did not speak their language (Pierotti 2011). Despite the fact that scientists are said to be objective and to "see their work in isolation- that is unconstrained by their own context...despite their careful definitions and their forced assertions, scholars are inevitably influenced at least as much by the common usage of the terms that they deploy, as they are by their more rarefied and specialized senses" (Ritvo 2010:4).

In any case, it appears that fish are fully capable of experiencing painful stimuli, and they respond to these stimuli in ways similar to responses shown by birds and mammals; i.e., avoiding areas where pain is experienced, rubbing the affected areas. If analgesics are applied, fish show a marked reduction in such behavior.

Braithwaite brings up the issue of objective emotion, in which the organism is in an emotional state that is obvious from its posture and appearance. Almost all animals, including invertebrates and possibly even plants, show this type of response. It is another issue, however, whether fish are capable of subjective emotion, which is "feeling what it is to feel 
something." This is a state in which an animal interprets and is aware of its state of discomfort, sort of the difference between stubbing your toe and cursing and jumping around (the objective response), and thinking, "My toe really hurts and I wish it would stop feeling this way" (the subjective response).

There seem to be variation among species of fishes in this ability to display apparent consciousness or sentience. Braithwaite provides a rather elegant example of whether or not fish are capable of considering possible alternative scenarios and modifying decisions based upon contingencies, in her description of interactions between moray eels and groupers. When prey pursued by groupers flee into crevices on coral reefs where the grouper cannot pursue, some groupers go and signal to morays, vigorously shaking their heads in rapid vertical motion. The moray can choose to ignore this, and some do, but other eels leave their crevices and follow the grouper, who leads them to the part of the reef where the smaller prey have taken refuge, at which point the grouper can actually point to particular holes using its head. The eel then enters the hole and about half the time it flushes the prey where it is caught by the grouper. It is assumed that many of the times when the prey does not flush, it is taken by the eel.

At the same time we were studying parental care in cichlids, we also studied group hunting behavior in Florida largemouth bass, which showed behavior that was somewhat analogous to the situation observed between groupers and moray eels. We observed largemouth bass in groups of 4-5 individuals surround a clump of aquatic vegetation, and then one individual would lunge into the vegetation, while its companions picked off small fish and invertebrates dislodged or startled by the rush (Annett 1998). We could not determine if individuals took different roles, but it seemed likely that the bass were trading off lunging and surrounding.

One situation quite similar to the cooperative interaction between the grouper and the moray is the observation derived from Indigenous knowledge traditions that badger and coyote were "friends" and hunted together (see pages 58-59 in Pierotti 2011). Film footage of this relationship can be seen in Yellowstone: Realm of the Coyote (National Geographic 1995). Empirical study has revealed that these two species truly are cooperative. Coyotes and badgers spend a lot of time wandering around together, but when they see ground squirrels, coyotes give chase. If the squirrel goes into a burrow, badgers will dig up the burrow, or both will dig together. If the squirrel stays in the burrow, badgers will often get it. If the squirrel attempts to escape by using another burrow exit, coyote often gets it and has a meal. Both coyote and badger catch more squirrels when they hunt together than when they hunt alone (Minta et al. 1992).

Even though it seems clear that fish can feel pain and seem capable of a wide range of complex social behaviors and emotional states, no one seems to raise the question of whether fish feel grief. We can't help but wonder what might be found if scientists looked more closely at monogamous species with strong pairbonds. Clearly when one partner was removed in our study of T. mariae, the remaining partner experienced considerable stress (Annett et al. 1999). If they had not had to work so hard to make up for their partner's absence, they might have shown behavior comparable to responses shown by monogamous birds who have lost a partner.

Grief is an unusual phenomenon; at one level it seems an obvious response to the loss of an individual with whom one has a social bond, but if this response becomes too consuming it can have serious negative implications for survival. The major question concerning the presence of grief in human versus nonhuman animals might be whether humans are the only species that can afford to indulge in extreme displays of grief.

The issue of whether grief can be found in nonhuman animals is well addressed by Barbara King, in her book, How Animals Grieve. King does a generally good job of presenting her arguments concerning the evidence for grief in nonhumans, although she has to rely a good deal on examples from domestic animals. Most of these examples take a similar form; i.e., two individuals, sometimes from different species or breeds, spend many years together. If one perishes, the other acts depressed, often refusing to eat, and its health may decline. However if another animal is introduced often the spirits of the survivor will pick up and they seem to return to "normal" after a while. As an anthropologist, King is most familiar with the primate literature, and draws numerous examples from this source as well. After all, the "likeliest targets of unconscious identification and projection [are] animals who were most like people, either because they looked like people, or because they were members of the same society. Animals outside these overlapping circles of familiarity were much less likely 
potential surrogates" (Ritvo 2010:8-9).

King does include other examples, but these are often from the usual set of suspects; e.g. elephants and dolphins, which seem to be among the few species that most humans are willing to accept into the pantheon of fellow grievers, and are allowed to have a theory of mind. One thing we found both interesting and perplexing is that in a discussion of the reaction of elephants to bones of their own kind, King discusses whether they recognize individual skulls. An experiment was carried out which suggested that although elephants can clearly distinguish between skulls of conspecifics and those of other species, they recognized skulls of elephants in general, but not of individuals. Why is this surprising? We doubt that most humans could recognize the skulls of departed family members in a group of skulls without resort to looking at teeth, which are the only part of the skull we see with any regularity while the individual is alive. After all, even Hamlet had to have the gravedigger identify Yorick's skull so he could soliloquize about it. With regard to recognition of dentition, it is clear that elephants recognize tusks from familiar individuals. We also suspect that spatial context is important to elephants. They know where members of their social groups have died, therefore encountering their skulls in a new location, as happened in the experiment, may only confuse them.

King describes extreme displays that can be shown over dead conspecifics in chimpanzees, including violence directed at the dead individual. She contends that this type of behavior is not observed in humans, which suggests she has not carefully surveyed the human literature. We are again provided the example of Flo and her son Flint, who apparently died of grief shortly after his mother passed. This example is compelling, but it generally leaves out the fact that Flint was the last male offspring of this prolific female, and her other older offspring did not die of apparent grief, however badly they may have felt concerning her passing.

Missing from King's book are some very strong examples from monogamous birds, even though she does discuss examples from geese and chickens. Safina (2002) describes very dramatic behavior in a pair of Laysan Albatross (Phoebastria immutabilis Rothschild Diomedeidae), involving grieving by a female who lost her first chick. This pair was closely observed by a couple upon whose land they were nesting. What was extraordinary in this case was the behavior by the male partner, who continued to help incubate the dead chick for several weeks to help the obviously grieving female cope, until she seemed to adjust to loss of her first offspring. This is crucial, because this species typically has lifetime pair-bonds that can last for several decades, and one of the major factors leading to pair-bond breakage is the loss of offspring early in the relationship.

From our own work, along with other scholars, we have observed what we considered to be "funerals" in Magpies (genus Pica Linnaeus Corvidae) and described the most dramatic example of this phenomenon that we observed in the Yellow-billed Magpie:

One day when RP was watching magpies feeding in an oak-savannah habitat (in Central California) an incredible ruckus broke out. A Cooper's Hawk (Accipiter cooperi Bonaparte Accipitridae), had attacked and killed a female magpie. Magpies from all over the area gathered in the trees around the kill site and chattered constantly while the hawk ate the magpie. This was not that surprising, animals often gather and observe a predator after it has taken a member of their group, however I did not expect what happened next. After the hawk left, the magpies flew down and walked over to the remains of the dead female. They no longer chattered, instead they muttered in low voices, like they were talking to each other. To my surprise, some magpies picked up feathers from the dead bird, took them into the trees, and stuck them there. After 15-20 minutes all the magpies except one flew away silently.

The only remaining bird was the mate of the dead bird. He picked up one of her primary wing feathers and carried it around with him for several days. When he stopped to eat he would put the feather down carefully and eat, then he would pick the feather up again and fly off with it. I realized that I was witnessing something akin to a funeral, or at least a celebration of a death, in a nonhuman. Other observers had described this behavior (Miller and Brigham 1988; Trost 1999), but they had not seen the feather carrying aspect (see pages 132-133 in Pierotti (2011).

Comparing our experience to accounts in King's book, this behavior seemed to have elements of a ceremony, which is why we described this as a 
"funeral." A “ceremony" conducted by nonhumans related to sudden death seems to fit clearly within the category of behavioral responses that reveal grieving in nonhumans.

King discusses the carrying of stillborn infants by monkeys, apes, and dolphins. Such behavior occurs in a wide range of species. We have observed the carrying of stillborn offspring by female Steller sea lions (Eumetopias jubatus Schreber Otariidae), and have photographic evidence of this behavior. Females carried their offspring with them for 2-3 days, picking them up in their mouths and carrying them by the scruff of the neck. For the record, carrying offspring in this fashion is not typical behavior in this species: despite being Arctoid carnivores, sea lions do not carry their offspring in their mouths when the young are alive. After stillbirths were the only times we observed this behavior.

King's accounts of grieving in primates might be strengthened by an example observed by Steve Green of the University of Miami. When he was working on Japanese Macaques (Macaca fuscata Blythe Cercopithecidae), Green observed a young female who had just lost her first infant. This female was alone at the time, and when she picked up her infant's body she began to wail in a way he not seen before (Green 1975). Within a few minutes there was a crashing in nearby bushes and another adult monkey came running up and threw her arms around the young female and held her while she wailed (S. Green, personal communication). Not surprisingly, this new female adult was the mother of the young female who had lost her infant, which suggests strongly that not only grief, but empathy and comfort to the grieving, might be components of nonhuman activity.

After reading these books, it seems obvious that yes, fish do indeed feel pain and are even capable of much more complex behavior. Similarly, a wide range of nonhuman species seem capable of complex emotions such as grief and even empathy. The real problem with identifying these complex behaviors seems to be a fear of "anthropomorphism," combined with a desire to please, or at least placate, economic and religious interests in Western European traditions.

By this reasoning, the only reason there is any debate over pain in fish is because of the way they are "harvested," a term implying that they are like agricultural plants rather than other vertebrates. Braithwaite points out that the equivalent of commer- cial fishing, especially with bottom trawls, would never be tolerated if it were applied to birds or mammals on land. This can also be seen in the fact that it is illegal to hunt in National Parks, but fishing is allowed. Even "catch and release" fishing, which is touted as a means of conservation, has serious problems in that many animals are seriously injured and left to die slow deaths (Pierotti and Wildcat 1999).

The irony is that this way of thinking owes much more to Descartes than to Darwin. Charles Darwin (1871) argued that humans and nonhumans shared emotional states and that the differences were of degree, not of kind. Despite constant repetition that humans are animals, and also that they are primates, "such assertions often seem defensive or even strident," because of the, "persistent reluctance to locate ourselves and our closest extinct relatives in the family Pongidae...rather than in the more exclusive family Hominidae, reserved for australopithecines and humans" (Ritvo 2010:3). Rarely has a 1\% difference between the total genomes of closely related species been used for such taxonomic grandeur (see also Diamond 1992). As a result, many scientists who allege that they are Darwinians seem to actually show strong creationist inclinations when it comes to discussing the similarities between our own emotional states and those of our nonhuman relatives.

It is time that we carefully evaluate the science and come to accept the fact that human emotions are not the result of special creation, but instead arise from a long evolutionary history and from shared traits. We should welcome the ability to situate ourselves in the larger world with our animal relatives. We hope that this will come to be regarded as something we already knew.

\section{References Cited}

Anderson, E. N. 1996. Ecologies of the Heart: Emotion, Belief, and the Environment. Oxford University Press, NY, NY.

Anderson, E. N. 2013. What Shapes Cognition? Traditional Sciences and Modern International Science. In Explorations of Ethnobiology: The Legacy of Amadeo Rea. Contributions in Ethnobiology, edited by Marsha Quinlan and Dana Lepofsky, pp 47-77. Society of Ethnobiology, Denton, Texas.

Annett, C.A. 1998. Hunting behavior of Florida Largemouth Bass (Micropterus salmoides floridanus) in a Channelized River. Environmental Biology of Fishes 53:75-87. 
Annett, C. A., R. Pierotti, and J. R. Baylis.1999. Male and Female Parental Roles in a Biparental Cichlid, Tilapia mariae. Environmental Biology of Fishes 54:283293.

Darwin, C. 1871.The Expression of Emotions in Man and Animals, Reprint 1998. Harper Collins, London.

Diamond, J. 1992. The Third Chimpanzee: The Evolution and Future of the Human Animal. HarperCollins Publishers, NY, NY.

Durham, Jimmy. 1983. Columbus Day. West End Press, Minneapolis, MN.

Green, S. 1975. Variation of Vocal Pattern with Social Situation in the Japanese Monkey (Macaca fuscata): a field study. In Primate Behavior: Developments in Field and Laboratory Research, Vol. 4, edited by L.A. Rosenblum, pp. 1-102. Academic Press, NY, NY.

Miller, W. R., and R. M. Brigham. 1988. "Ceremonial" Gathering of Black-billed Magpies, Pica pica, After the Sudden Death of a Conspecific. Murrelet 69:7879.

Minta, S. C., K. A. Minta, and D. F. Lott. 1992. Hunting Associations between Badgers and Coyotes. Journal of Mammalogy 73:814-820.

Goldberg, Rob and John Rubin. 1995. Yellowstone: Realm of the Coyote. National Geographic Video.
Pierotti, R. 2011. Indigenous Knowledge, Ecology and Evolutionary Biology. Routledge, Taylor and Francis Group, New York.

Pierotti, R. and C. A. Annett. 1994. Patterns of Aggression in Gulls: Asymmetries and Tactics in Different Roles. Condor 96:590-599.

Pierotti, R. and C. A. Annett. 1995. Western Gull (Larus occidentalis). No. 174. The Birds of North America, edited by A. Poole and F. Gill. The Academy of Natural Sciences, Philadelphia and American Ornithologists' Union, Washington D.C.

Pierotti, R., C. A. Annett, and J. L. Hand. 1996. Male and Female Perceptions of Pair-Bond Dynamics: Monogamy in the Western Gull. In Feminism and Evolutionary Biology, edited by P.A. Gowaty, pp. $261-$ 275. Chapman and Hall Press.

Pierotti, R. and D. Wildcat. 1999. Connectedness of Predators and Prey: Native Americans and Fisheries Management. Fisheries 24(4):22-23.

Ritvo, H. 2010. Nobel Cows and Hybrid Zebras: Essays on Animals and History. University of Virginia Press, Charlottsville, VA.

Safina, C. 2002. The Eye of the Albatross. Henry Holt and Co., NY, NY.

Trost, C. H. 1999. Black-Billed Magpie. No. 389. The Birds of North America, edited by A. Poole and F. Gill. The Academy of Natural Sciences, Philadelphia and the American Ornithologists' Union, Washington, D.C. 